\title{
RADIOCARBON DATING WITH THE QUANTULUS IN AN UNDERGROUND COUNTING LABORATORY: PERFORMANCE AND BACKGROUND SOURCES
}

\author{
ROBERT M KALIN and AUSTIN LONG \\ Laboratory of Isotope Geochemistry, Environmental Radioisotope Center \\ University of Arizona, Tucson, Arizona 85721
}

ABSTRACT. The University of Arizona Radiocarbon Laboratory purchased a state-of-the-art LKB Quantulus LSC and placed it into a new underground counting chamber. We have investigated the performance of the Quantulus in this setting comparing different vial types, checking background sources and experimenting with sample size.

\section{INTRODUCTION}

The use of massive physical shielding to reduce the cosmic-ray component of background in underground counting labs has been reported by many authors (Schotterer \& Oeschger, 1980; Loosli et al, 1980; Calf \& Airey, 1982; Bowman, 1989). The underground counting chamber at the University of Arizona was built as part of the new Gould - Simpson Science Building on campus. This lab has $10 \mathrm{~m}$ of overburden and is climate controlled. The temperature within the lab is kept at a constant $15^{\circ} \mathrm{C}$. Humidity is rarely a problem in the desert southwest, but the chamber has two dehumidifiers to ensure that humidity is kept to a minimum. This strict climate control allows the interior of the liquid scintillation counters to be kept at $7^{\circ} \mathrm{C}$, just above the freezing point of benzene. A Packard $460 \mathrm{C}$ liquid scintillation counter (LSC) was moved from its location on the basement floor of the old Geology Building and placed in the underground counting lab. A series of background samples for which the count rate was well known averaged $40 \%$ lower in the underground site than in the basement of the old building.

The University of Arizona Radiocarbon Laboratory purchased an LKB Quantulus in February 1986 and placed it in the new underground chamber. The performance of the counter was not tested at surface level due to the difficulty of moving the $880 \mathrm{~kg}$ shield into place. The background count rate quoted in the sales brochure for $3 \mathrm{ml}$ of benzene in a teflon vial was 0.25 counts per minute (cpm). This counter was purchased to increase the capabilities of our radiocarbon lab.

\section{VIAL SELECTION}

Included with the Quantulus were special teflon vials ranging in capacity from 3 to $20 \mathrm{ml}$. These vials provide the optimal background and figure of merit values when counting samples in the Quantulus. We use $3 \mathrm{ml}$ of benzene in all our counters, and therefore, chose the $3 \mathrm{ml}$ vials for study.

The background attained in the highest efficiency window with these vials was $0.170(97) \mathrm{cpm}$ with a standard deviation of $0.001(73) \mathrm{cpm}$. Com- 
paring this value with the quoted background, we find a $32 \%$ reduction of background in the underground lab; this is comparable to the $40 \%$ decrease found with the Packard 460C LSC. This low background is excellent for ${ }^{14} \mathrm{C}$ determinations, but for reasons to be explained, we found the vials unsuitable for routine use.

Figure 1 shows the spectrum produced by counting the same Oxalic Acid I (OXI) sample in two different teflon vials supplied, one from vial no. 10 , and one from vial no. 2 . The high-energy end of the spectrum from vial 2 is compressed, as compared to vial 10 . There is a $2 \%$ efficiency difference between these vials, which is probably due to differences in the density of the teflon used in the manufacture of the vial (L Kaihola, pers commun, 1988). This difference decreased the photon transmission through the vial wall, which shifted the spectrum to lower energy, but, due to the amplifier gain cutoff in the selected high gain mode, the lower energy limit is fixed. Thus, we see a compression of the energy spectrum in the highenergy region for the vials with denser teflon walls.
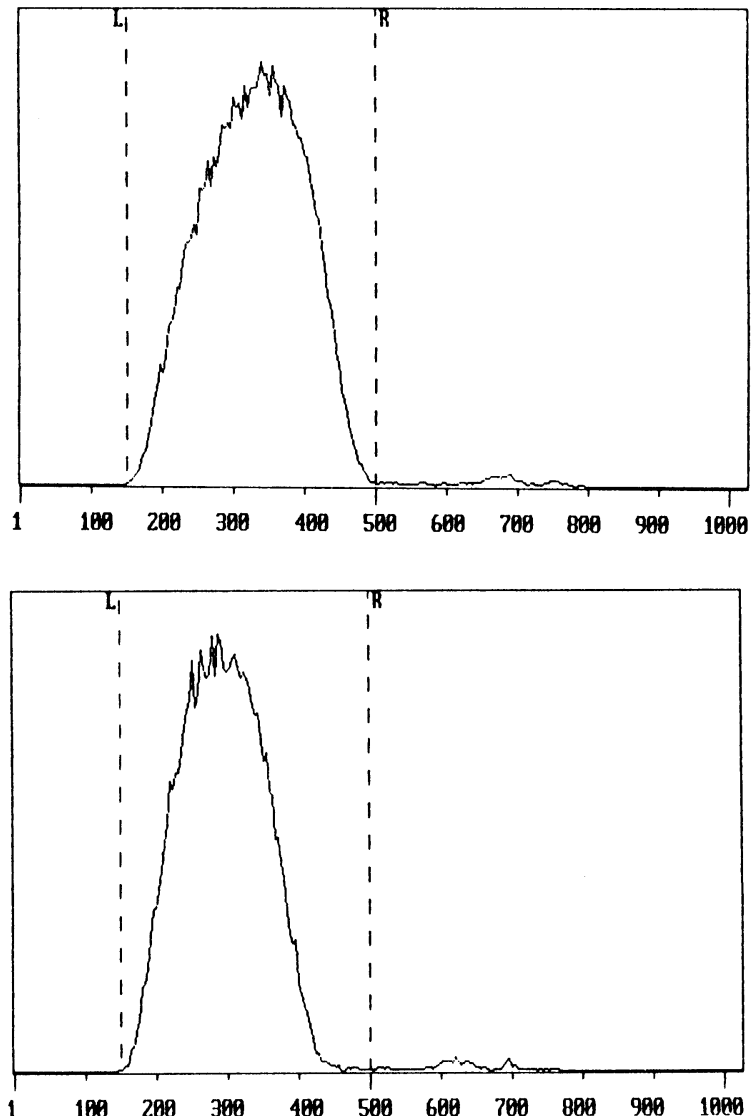

Fig 1. The same oxalic acid sample counted in two of the teflon vials supplied with the Quantulus 


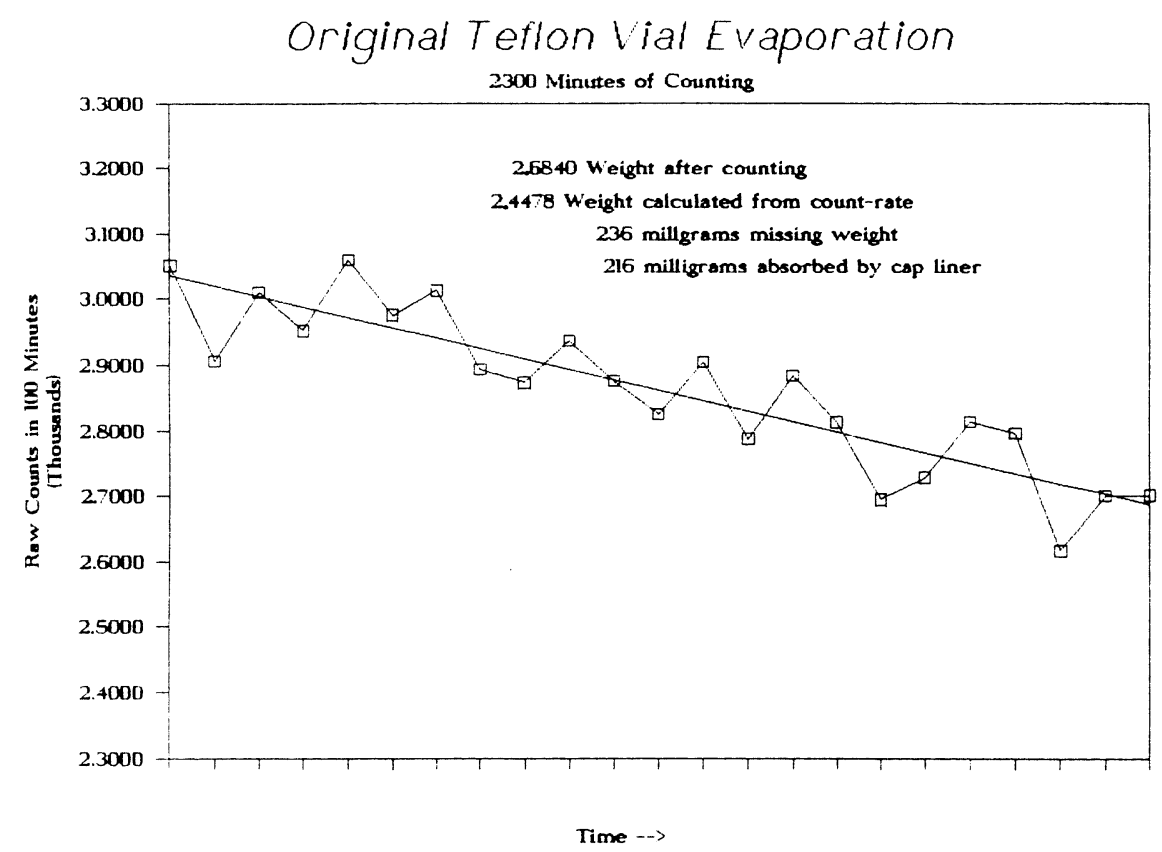

Fig 2. Best-fit line for a series of counts of an oxalic acid standard in a teflon vial

Figure 2 shows a decrease in the count rate of an OXI sample in a teflon vial counted for two weeks. The weight loss from the vial, $42.8 \mathrm{mg}$, did not account for the decrease in count rate. We attempted to reconcile this difference in count rate as follows. The weight of sample in the vial after the counting period was $2.6840 \mathrm{gm}$. The final count rate from the best-fit line through the data was used to calculate the weight of benzene-producing events in the vial at the end of the counting period. The calculated weight was $2.4478 \mathrm{gm}$. The sample's silicone - teflon cap was weighed after it was taken from the vial, and then weighed again after it had been dried. The weight of benzene absorbed in the cap liner was $216 \mathrm{mg}$; the difference between the true weight and the calculated missing weight was $236 \mathrm{mg}$. We assume that the $20 \mathrm{mg}$ of benzene for which we cannot account may have been condensed on the cap out of contact with the sample benzene, thus lowering the efficiency of counting. Next, we placed a silicone-teflon cap liner into a beaker filled with benzene and found that the cap absorbed so much benzene that the silicone swelled and deformed the shape of the liner.

The teflon vials are unsuitable for our use during routine counting not only because of the reasons discussed, but also because of the rigorous cleaning procedures needed to ensure sample integrity. The very low backgrounds using the teflon vials would be useful for high-precision dating. The number of these samples counted in a year is so small that the cleaning procedure is not so crucial; evaporation is the major concern. To use the teflon vials for high-precision dating, we designed the vial insert seen in 


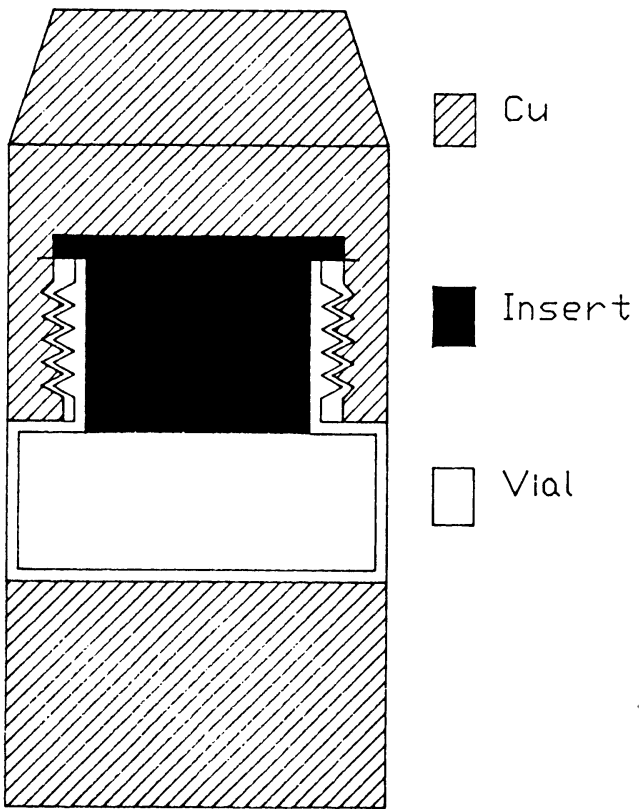

Fig 3. Cross-section of teflon vial with teflon insert

Figure 3. This insert kept benzene from condensing on the cap, out of contact with the solution, decreased evaporation to $7 \mathrm{mg}$ of benzene over an 8000 min counting interval and eliminated the absorption of benzene into the cap material. We calculated that, when using five matched teflon vials with these inserts, samples can be counted to better than $2 \%$. This research, which originally used gas proportional counting, will be reinstated, when we finish our system, to measure ${ }^{13} \mathrm{C} /{ }^{12} \mathrm{C}$ ratios on benzene.

We found that by selecting glass vials carefully, and using teflon cap inserts, there is no evaporation measurable when counting. Ca 300 glass vials were examined for use. Each of the vials were checked for even tops and scratches or flaws in the glass. The flawed vials were used for other purposes. The good vials were masked throughout except for the lowest $1.3 \mathrm{~cm}$. Each of these glass vials was checked for uniform background and efficiency. A set of vials with the same efficiency and background were chosen and each vial was weighed after each test to check for evaporation. Only the vials that showed no loss of mass were selected. Of the 300 or so vials we began with, 60 were selected for routine counting. Each time the sample vial was cleaned, a new teflon cap liner was washed in benzene and installed. In this way, we were able to eliminate the use of indium foil seals suggested by Otlet and Slade (1974). 


\section{BACKGROUND SOURCES}

In Figure 4, we have plotted the count rate in the active shield $v s$ the background count rate in a glass vial. The count rate in the shield averages ca $500 \mathrm{cpm}$ and this signal is scaled to the background count rate. The background sample averages an event once every $2-3 \mathrm{~min}$. These data were collected for ten days; no strong correlation could be found between the count rate in the shield and background. The massive physical shielding and control of climate in the underground lab has attenuated the cyclic variations of background we found in the old counting lab.

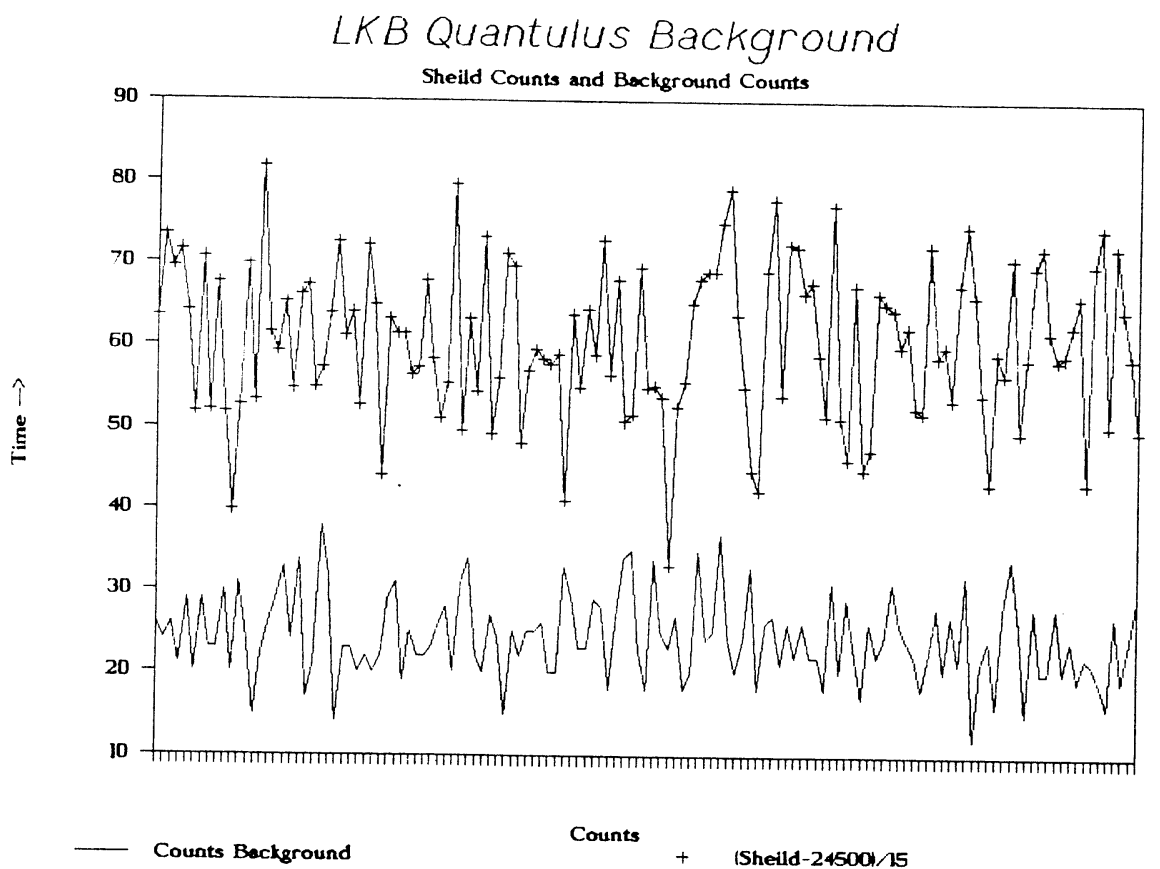

Fig 4. Count rate in the shield plotted with the background count rate in a glass vial for 10 days

The average background count rate of the $3 \mathrm{ml}$ teflon vials over 2500 min will produce 427 events. A completely black vial was counted for over $10,000 \mathrm{~min}$ to check for events that would be interpreted as real events. A black vial would only allow one photo tube to see cherenkov photons; thus, only electronic noise or the chance particle that travels through the counter along the plane of the photo tubes will produce an event. We found an average of one event every $2500 \mathrm{~min}$ due to either of these possibilities. We then counted an empty teflon vial over 10,000 min and found we could expect an average of 12 additional events in 2500 min of counting. We attributed these events to optical crosstalk. We filled a $3 \mathrm{ml}$ vial with background benzene without adding the scintillant and counted it as before. The 
expected average of 77 additional events, in $2500 \mathrm{~min}$, we postulate are chemical or cosmic-ray interactions in benzene that produce photon pulses similar to those from the sample benzene with the scintillant. Finally, and surprisingly, we analyzed a quantity of butyl-PBD scintillant used in our lab for ${ }^{14} \mathrm{C}$, and determined that it has a finite activity of $0.5(5) \%$ modern. This activity, with the $0.95 \mathrm{wt} \%$ concentration we use, would introduce five events to the background count rate over 2500 min. Summing all of these contributions, we have remaining 333 events, or $0.128 \mathrm{cpm}$. These events may be due to: 1) a $<100 \%$ efficient anticoincidence shield, 2) construction materials not devoid of radioactivity, 3 ) possibly chemical blank material not devoid of ${ }^{14} \mathrm{C}$, or 4) an unknown source.

\section{COUNTING PERFORMANCE}

The Quantulus has been extremely stable during the past two years. The spectrum of OXI standard and background samples are constantly checked with time. We have yet to find any change in the spectrum shape. The sample chamber was opened once to check for the accumulation of dust and we found little, indicating that the climate control in the underground lab helps to control dust as well. The average background in the window with highest efficiency is $0.494 \mathrm{cpm} \pm 0.006(75) \mathrm{cpm}$. The standard

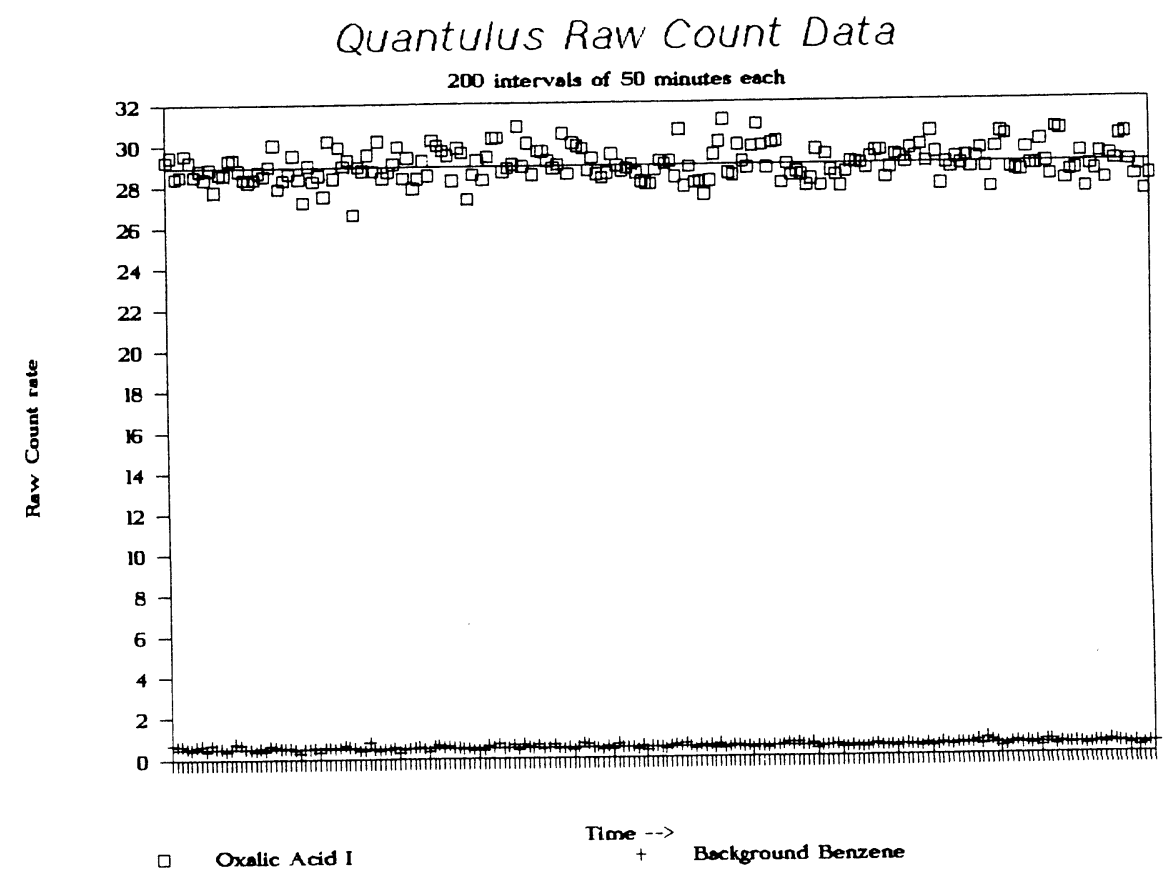

Fig 5. Oxalic Acid I and background raw data collected on the same samples for 3 months plotted with their respective average values 
deviation of the background count rate is slightly better than the \pm $0.007(02) \mathrm{cpm}$ predicted by normal statistics. The average count rate of a $3.0 \mathrm{ml}$ OXI benzene sample was 28.943(2) $\pm 0.0543(4)$ above background. The stability of counting with the Quantulus can be seen in Figure 5 by noting the tight cluster of the individual 50-min counting intervals around the mean value. These data were collected on an OXI and background samples counted with other samples, standards and backgrounds over a 3month period. The counting stability we achieve in the underground lab using the Quantulus results in a lower limit of $\pm 4 \%$ error on routine undiluted modern samples counted $2000 \mathrm{~min}$. We can obtain a finite maximum age of $53,400 \mathrm{yr}$ for a sample size of $2.6 \mathrm{~g}$ of carbon counted $2000 \mathrm{~min}$. Calculations show that the Quantulus in the underground lab is capable of determining ${ }^{14} \mathrm{C}$ activity to better than $2 \%$ o by counting samples 8000 min or more.

\section{SMALL SAMPLES}

With the very low backgrounds and stability of the counter, we are also able to count very small samples. We routinely count samples as small as $500 \mathrm{mg}$ of carbon. These samples are diluted to $2.7 \mathrm{~g}$. We have conducted experiments counting samples as small as $80 \mathrm{mg}$. These samples are counted in quartz spectrophotometric cells of 1 or $2 \mathrm{~mm}$ path length. A special vial holder was manufactured using low oxygen copper. This sample holder was machined to allow the maximum surface of the vial to be seen by the phototubes, and to block crosstalk. The background count rates measured with this system have been averaging $0.16 \mathrm{cpm}$ in a $71 \%$ efficient window. Additional data must be collected before a statistically accurate average for this technique can be quoted. With this technique our lab will routinely count samples as small as $250 \mathrm{mg}$ of carbon without diluting the samples in the second Quantulus now on order.

\section{DATE CALCULATION ROUTINES}

We have written our own data reduction routines for the calculation of ${ }^{14} \mathrm{C}$ ages. Our routines read each individual spectral information file for count time and counts within the specified counting window. The counts per minute are calculated for each interval at 32-bit precision. The average, standard deviation, Poisson limit and a graph of the interval distribution over $3 \sigma$ are printed out, and a LOTUS input file containing all these data is written to the computer disk. The LOTUS file is used within a macro to recalculate the running standard and background information, pause for input relating to sample information, then calculate and print the age of the sample. We use this method because of inconsistencies in ${ }^{14} \mathrm{C}$ results between the Quantulus age calculation program we received in 1986 and our calculation routines. The calculated ${ }^{14} \mathrm{C}$ result for sample A-5092 differs between the two programs as seen in Figure 6. We calculate an age of 520 \pm 50 for this sample and the Quantulus age program calculates $910 \pm 50$. This sample of corn cob, submitted by E Charles Adams and illustrated here with his permission, is associated with prehistoric ceramics, and is expected to be 


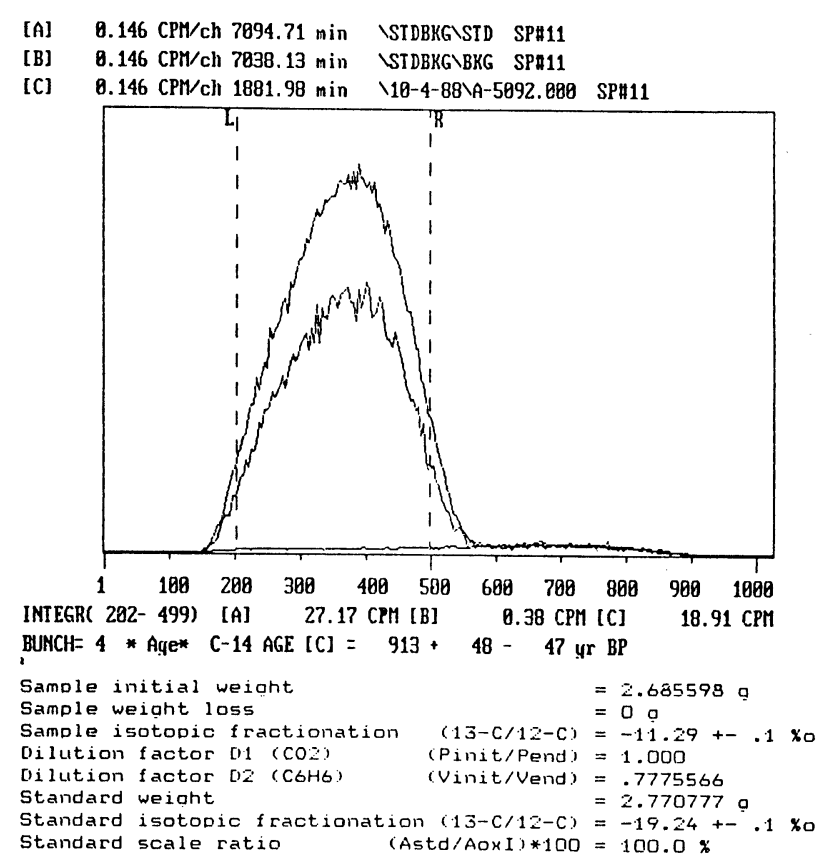

Fig 6. Age calculation output of sample A-5092 using the program supplied with the Quantulus as compared to the age calculated in our lab

between $\mathrm{AD} 1300$ and 1350 . The calibrated time ranges of the date we reported, as determined using the Stuiver and Reimer (1986) Calib program, lie between AD 1331-1345 and 1394-1433 at 1б. The second time range can be ignored based on archaeological information from this site (Adams, pers commun) and our calibrated age lies within a 14-yr time range within expectations. The original Quantulus computer program calculates an age well outside of this range. Further communication with LKB has uncovered a minor error in the first version of the Quantulus software, which is no longer distributed. Calculations using an updated version of the program, which account for this error, produce ${ }^{14} \mathrm{C}$ results that agree with ours.

\section{CONCLUSION}

The background of the Quantulus in the underground lab was better than the specifications we were originally quoted. The teflon vials supplied with the counter are difficult to use and can be quite time consuming. For routine counting, we found that glass vials with teflon liners did not have evaporation problems, and have quite acceptable counting characteristics. The source of $22 \%$ of the background count rate can be attributed to electronic noise, physical or chemical events with benzene, crosstalk, and contamination from the scintillant. More studies of background sources need to be completed. The Quantulus enabled us to decrease the size of sample required for routine LSC. Finally, we wrote our own data reduction routines. 


\section{ACKNOWLEDGMENTS}

The authors would like to acknowledge Herbert Haas for sharing his knowledge of counting small samples using LSC. We would also like to acknowledge the State of Arizona for support of this project.

\section{REFERENCES}

Bowman, S, 1989, Liquid scintillation counting in the London Underground: Radiocarbon, this issue.

Calf, G E and Airey, P L, 1982, Liquid scintillation counting of C-14 in a heavily shielded site, in Archeometery: an Australian perspective: Canberra, Australian Natl Univ Press, p 351356.

Loosli, H H, Heimann, M and Oeschger, H, 1980, Low-level gas proportional counting in an underground laboratory, in Stuiver, $\mathrm{M}$ and $\mathrm{Kra}, \mathrm{R} \mathrm{S}$, eds, Internatl ${ }^{14} \mathrm{C}$ conf, $10^{\text {th }}$, Proc: Radiocarbon, v 22, no.2, p 461-469.

Otlet, R L and Slade, B S, 1974, Harwell radiocarbon measurements I: Radiocarbon, v 16, no. 2, p 178-191.

Schotterer, U and Oeschger, H, 1980, Low-level liquid scintillation counting in an underground laboratory, in Stuiver, $\mathrm{M}$ and $\mathrm{Kra}, \mathrm{R} \mathrm{S}$, eds, Internatl ${ }^{14} \mathrm{C}$ conf, 10th, Proc: Radiocarbon, v 22, no.2, p 505-511.

Stuiver, M and Reimer, P J, 1986, A computer program for radiocarbon age calibration, in Stuiver, M and Kra, R S, eds, Internatl ${ }^{14} \mathrm{C}$ conf, 12th, Proc: Radiocarbon, v 28, no. 2B, p $1022-1030$. 